\title{
Review
}

\section{Critique on the couch: Why Critical Theory needs psychoanalysis}

\author{
Amy Allen \\ Columbia University Press, New York, 2021, vii+265pp., ISBN: \\ 978-0231198608
}

Contemporary Political Theory (2022) 21, S134-S137. https://doi.org/10.1057/s41296021-00484-y; published online 31 March 2021

The title of this book suggests a psychoanalysis of critique, as if "critical theory needs psychoanalysis' in the sense that it needs to be psychoanalyzed. Certainly, the book carefully evaluates critical theory; Allen finds, in particular, that the following 'problems ... have arisen within critical theory as an intellectual project: normative idealism, developmentalism, utopianism, and rationalism' (p. 187). But these are, of course, not psychoanalytic assessments. The one moment when critique does seem to be on the couch is in the book's conclusion, which identifies a 'tendency' among some contemporary critical theorists to indulge in 'the seductive comforts and satisfactions of pathologizing those on the other side' (p. 192). Yet even here, Allen cites just one example of such indulgence, and refrains from probing its deeper motives. After all, the conclusion also counsels readers to 'resist the temptation to use psychoanalysis as a tool for diagnosing them' (p. 192). It makes sense that the book does not offer a diagnosis of critical theorists.

What the book offers instead are two arguments. The first is that psychoanalysis can provide critical theory with a suitably 'realistic' philosophical anthropology and an engaging set of normative aspirations. Such conceptual resources will help critical theorists avoid the problems identified above; they allow critical theory 'to temper its tendencies toward normative idealism, to rethink its developmental models of self and society, and to theorize the aims and methods of critique beyond utopianism and rationalism' (p. 24). For this to happen, Allen contends, critical theorists ought to draw less on Freud (or at least on what she calls the 'official' Freud) and more on Melanie Klein. Much of the book is devoted to developing Klein's metapsychology - especially her language of 'positions' and her take on drive theory - and its lessons for ethical and political reflection.

More precisely, the first four chapters of the book each draw forth one 'resource,' or set of resources, from the work of Klein (and, to a lesser extent, from compatible lines of thought in the work of Freud, Lacan, Adorno, and their commentators). Chapter one elaborates Klein's view of the psyche, which gives us

(c) 2021 The Author(s), under exclusive licence to Springer Nature Limited. 1470-8914 Contemporary Political Theory Vol. 21, S3, S134-S137

www.palgrave.com/journals 
a picture of the human that reckons with its ambivalent passions, its intersubjective constitution, and its deployment of 'phantasy', not just reason, in dealing with the world. Chapter two presents Klein's conception of ego integration, and of psychic development more generally, as consisting not in the progressive restraint of the drives but in an expansion of the ego's capacities to abide the complexity, strife, and challenges to self that characterize all social experience. Chapter three develops Klein's rejection of a 'stage' model of psychic development in favor of a 'positional' model, which allows us to conceive individual and social progress without recourse to an invariably racist notion of the 'primitive' as their negative measure. And Chapter four examines Klein's accounts of sublimation, creativity, and reparation to provide a sketch of a flourishing society that is not utopian, yet still attractive as an aspiration to be realized.

The book's fifth chapter and conclusion advance a second argument. Here, Allen contends that psychoanalysis is not just a resource but a model for critical theory. She notes that this is not a new idea but argues that previous efforts to analogize critique to psychoanalysis have been hampered by an overly rationalist view of the latter. On this view, which Allen attributes to Jürgen Habermas, Axel Honneth, and Robin Celikantes, psychoanalysis resolves symptoms by offering 'rational insights' to the patient. These insights bring the sources of the symptoms to light, and this illumination itself provides relief. But, as Allen points out, even Freud did not see treatment in this manner. For most of the canonical analysts, 'analysis works (if and when it does work) first and foremost through the transference, not through the power of rational insight' (p. 153). Hence, in recommending an 'analogy between psychoanalysis and critique,' Allen calls for something like the establishment of a transferential relationship - as opposed to a lecturing or judgment-laden one between critical theorists and those they interpret. 'To establish something like a transference relationship in the context of critical theory would mean simply to bring into view, through the interaction between critical theorists and social actors, the actors' distinctive, idiosyncratic way of experiencing the world as precisely that' - that is, as contingent and constructed rather than absolutely valid. 'Doing so thus reveals this structure of experience as something that is open to practical transformation' (p. 171). Revelation of perspectival contingency, not rational instruction or pathologizing diagnosis, should be the product of critique.

Allen's central point here is that effective interpretation requires, as a prior condition, the building of an intimate relationship between the one who gives and the one who receives the interpretation. 'Taking seriously the way that the analyst is necessarily implicated in the transferential relationship suggests by analogy a view of the theorist as an engaged participant in ongoing social and political struggles' (p. 175). Presumably, the necessity of this participatory relation or 'alliance' (p. 183) as a condition for meaningful critique is what makes Allen so wary of diagnostic language. Discussing tendencies toward demonization, supremacism, and hostility in contemporary right-wing politics, Allen insists that

(C) 2021 The Author(s), under exclusive licence to Springer Nature Limited. 1470-8914 Contemporary S135 Political Theory Vol. 21, S3, S134-S137 
'the idea here is not to diagnose particular individuals, groups, or political movements or parties as being stuck in the paranoid-schizoid position,' but to talk 'about certain logics that continually reemerge in and shape politics in the present,' and to do this in a way that acknowledges that 'everyone has the tendency to fall back into the paranoid-schizoid mode' (pp. 192-193). For critical theory cannot risk alienating those it interprets. To do so would be to break, or at least strain, the basic alliance between theorists and social actors. And that would be to jeopardize whatever chance there is for critique to make a political difference.

As persuaded as I am by the book's first argument - that psychoanalysis in a Kleinian vein offers rich conceptual resources for contemporary critical theory - I wonder about this second proposal. In the case of psychoanalysis, the establishment of transference depends on its own prior conditions: The patient seeks out therapy, or is referred to therapy, primarily to address suffering. The patient and the analyst share an institutional space that facilitates intimacy. The patient more or less believes in the coherence of the analyst's program for relief. None of these conditions really hold for the relation between critical theory and the wider political world. To be sure, the analogy need not be perfect. But if analysts themselves have reflected so extensively on the material conditions of the transference - from the seating arrangement in the office to the use of the fee - this is because facilitating a bond in which the patient's idiosyncratic constructions of the world can be grasped as such is not easy.

More to the point, such a bond is not possible absent certain institutional conditions. There are, of course, rich exchanges between activists and theorists in our time, and many theorists who consider themselves engaged participants in politics. Yet most political actors are well outside the orbit of critical theory, and most critical theorists are university professors. Where is the social-institutional setting that would bind these two groups together, and this in such a way that the critic could effectively identify and reveal to political actors the contingency of their worldviews and dreams? Are we imagining a quasi-ethnographic encounter? Activists invited to symposia, or scholars out in the streets? Or perhaps the establishment of new cultural institutions under the rubric of public humanities? These are not rhetorical questions, but ones we need to answer in order to breathe life into Allen's brief. At a time when university employment is scarce for critical theorists (and many others), imagining new places for critical theory to do its work in the world is an essential activity.

If we could establish such new places, the worry about alienating political actors with diagnostic language would likely be attenuated. While a harsh diagnosis can be a condemnation, it can also serve to define and delimit an aspect of oneself and thus enable its amelioration. The problem is not that diagnosis is inherently offensive, but that the distance that Allen perceives between critical theory and the political world makes the condemnatory effect more likely. It is one thing to be judged sick by one's analyst, or even an intimate partner. It is another to be judged 
by a stranger, credentialed or not. I am not sure that the best solution is to narrow the distance between theory and politics, but I am convinced, reading Allen, that the distance requires thought. Allen pushes us to ask: what relation must critical theorists have to what they study for their work to be transformative, and not only 'insightful'? That is a vital question, to be worked out both philosophically and through institutional experimentation.

Publisher's Note Springer Nature remains neutral with regard to jurisdictional claims in published maps and institutional affiliations.

Jaeyoon Park

University of California, Berkeley, Berkeley, CA 94720, USA jaeyoonpark@berkeley.edu 